Review began 02/20/2022 Review ended 02/21/2022 Published 02/25/2022

๑) Copyright 2022

Hussain et al. This is an open access article distributed under the terms of the Creative Commons Attribution License CC-BY 4.0., which permits unrestricted use, distribution, and reproduction in any medium, provided the original author and source are credited.

\section{An Analysis of the Comparative Efficacy Between a Third-Generation and a Second-Generation Supraglottic Airway Device in Patients Undergoing Laparoscopic Cholecystectomy}

Darvish Hussain ${ }^{1}$, Raksha Kundal ${ }^{1}$, Anil Kumar ${ }^{1}$, Nikki Sabharwal ${ }^{2}$

1. Anaesthesiology, Lady Hardinge Medical College, New Delhi, IND 2. Anaesthesiology, Vardhman Mahavir Medical College and Safdarjung Hospital, New Delhi, IND

Corresponding author: Anil Kumar, akdranil@gmail.com

\section{Abstract}

\section{Background and objective}

Supraglottic airway devices are extensively used nowadays to secure the airway and minimize postoperative airway-related complications. This study aimed to evaluate whether the Baska ${ }^{\circledR}$ mask (BM) provides higher seal pressure and a better first-time insertion compared to the laryngeal mask airway (LMA) ProSeal ${ }^{\mathrm{TM}}$ (LMA-P) in adult laparoscopic cholecystectomy.

\section{Methodology}

This prospective, randomized, single-blinded interventional study was performed after obtaining ethical approval from the Institutional Ethics Committee at the Vardhman Mahavir Medical College and Safdarjung Hospital, New Delhi. Sixty adult patients of both genders scheduled for laparoscopic cholecystectomy under general anesthesia were divided into two groups, with 30 patients in each group. Our study observed the number of insertion attempts, time of insertion, oropharyngeal seal pressure (OSP), number of patients requiring manipulation for proper placement of supraglottic airway devices, and ease of insertion.

\section{Results}

There were no significant differences in terms of insertion attempts, ease of insertion, and laryngopharyngeal morbidity between the groups. The mean OSP at five minutes was $31.55 \pm 2.23 \mathrm{~cm} \mathrm{H}_{2} \mathrm{O}$, and that at 30 minutes was $35.86 \pm 3.70 \mathrm{~cm} \mathrm{H}_{2} \mathrm{O}$ in the BM group, while in the LMA-P group, it was 24.17 $\pm 3.74 \mathrm{~cm} \mathrm{H}_{2} 0$ and $25.97 \pm 3.79 \mathrm{~cm} \mathrm{H}_{2} 0$ respectively ( $\mathrm{p}<0.001$ ). In our study, the trend of OSP continued to increase in the BM group more than in the LMA-P group during surgery.

\section{Conclusion}

The BM provided better OSP than the LMA-P, which was observed throughout the surgery.

Categories: Anesthesiology, General Surgery

Keywords: laryngopharyngeal morbidity, laparoscopic cholecystectomy, ease of insertion, oropharyngeal seal pressure, proseal lma, baska mask

\section{Introduction}

Supraglottic airway devices have been used extensively to manage various laparoscopic surgeries [1]. Adequate (mean value: 19.5-21.3) oropharyngeal seal pressure (OSP) is the key to maintaining optimal ventilation and airway protection from aspiration [2]. The recently developed Baska ${ }^{\circledR}$ mask (BM) is a singleuse device with a non-inflatable cuff made of silicone [3]. This device takes the shape of a supraglottic airway and inflates and deflates with positive pressure ventilation, thereby preventing leaks. In addition, it contains side channels for suctioning aspirates, oesophageal drains, and an integrated bite block. It also has a second oropharyngeal curve that can be manipulated by pulling the tab of the BM. The second-generation laryngeal mask airway (LMA) has been designed to provide a higher airway seal and is relatively safer because it has a gastric channel [4].

There is scant data in the literature regarding the comparison between these two devices in adult laparoscopic cholecystectomy. In light of this, we conducted this study with the primary aim of comparatively evaluating the seal pressure of the BM with that of the LMA ProSeal ${ }^{\mathrm{TM}}$ (LMA-P). Secondary objectives were the comparative evaluation of ease of insertion, the time required for successful placement, percentage of successful first attempts, number of attempts required for insertion, and manipulation, if any, needed for the placement of these two devices. We hypothesized that by virtue of having a non-inflatable 


\section{Cureus}

cuff and insertion tab, the BM might have higher OSP and enables easier insertion than LMA-P in adult patients undergoing laparoscopic cholecystectomy.

\section{Materials And Methods}

This prospective randomized controlled trial was conducted at a tertiary care center in India after gaining approval from the hospital ethics committee (IEC/VMMC/SJH/Thesis/Oct 2017-015). After obtaining written informed consent, we analyzed 60 patients (Figure 1; consort flow diagram) with the American Society of Anesthesiologists (ASA) physical status I or II who were aged 18-65 years and scheduled for elective laparoscopic cholecystectomy. We excluded patients with an anticipated difficult airway, high risk of aspiration (gastroesophageal reflux or treated disease), preoperative sore throat/upper respiratory tract infection, BMI $>30 \mathrm{~kg} / \mathrm{m}^{2}$, and those who refused to provide informed consent. The patients were divided into two groups: the BM group and the LMA-P group. Randomization was performed using a computergenerated random number table, and the devices were allocated using the sealed envelope technique. Although blinding was not possible during device insertion, it was maintained during data analysis.

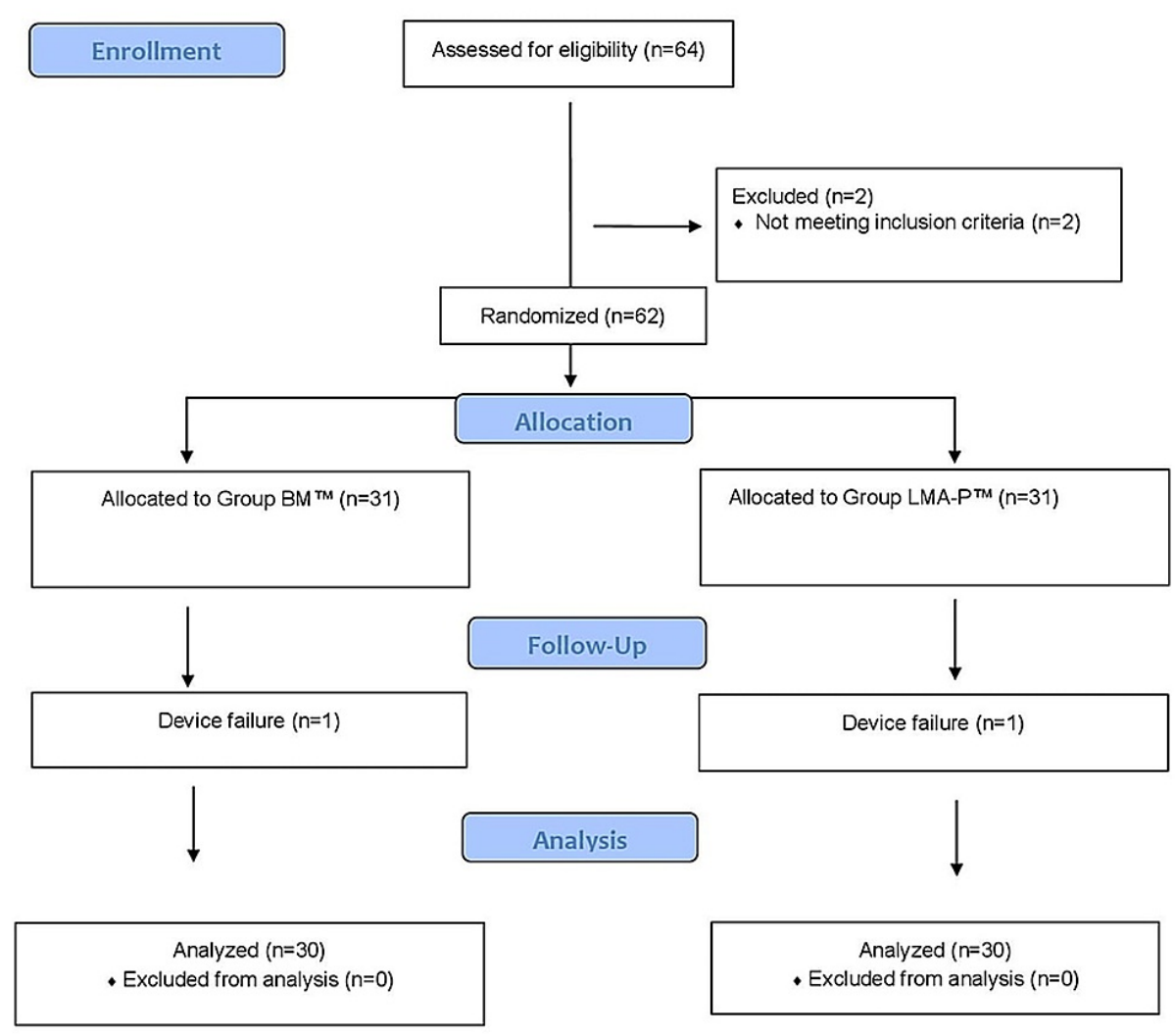

\section{FIGURE 1: Consort flow diagram}

BM: Baska mask; LMA-P: laryngeal mask airway ProSeal

On arrival in the operating room after being connected with standard monitors, each patient received general anesthesia with injection fentanyl $2 \mu \mathrm{g} / \mathrm{kg}$ body weight and propofol $2 \mathrm{mg} / \mathrm{kg}$ body weight and using vecuronium bromide as a muscle relaxant intravenously. Face mask ventilation was performed with $\mathrm{O}_{2}, \mathrm{~N}_{2} \mathrm{O}$ (1:1), and isoflurane $0.8-1.2 \%$ for three minutes, and then an appropriate airway device as per the allocated group was inserted. All supraglottic device insertions were performed by anesthesiologists trained in the insertion of the BM and LMA-P in adult patients before the start of the study. The size of the devices was decided as per the patients' weight and manufacturers' recommendations.

The cuff of the LMA-P was fully deflated, the dorsal surface was lubricated with water-soluble jelly, and the device was inserted with the help of an introducer with the patient's head and neck in sniffing position [4]. After placement, the cuff of the LMA-P was inflated with air to $60 \mathrm{~cm} \mathrm{H}_{2} \mathrm{O}$ and maintained at this pressure throughout anesthesia using a cuff pressure gauge (Mallinckrodt Laboratories, Neunkirchen-Seelscheid,

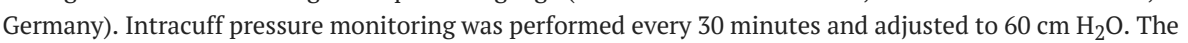
BM was lubricated with water-soluble lubricating jelly on the ventral surface; A BM of appropriate size was 
Under adequate depth of anesthesia, the proximal firmer part of the mask was compressed between the thumb and two fingers, and the device was advanced towards the hard and soft palate till resistance was felt; gentle pulling of the tab on the device was used to increase the palatopharyngeal curve to assist insertion. The ease of insertion was graded according to the resistance felt during insertion - grade I: no resistance to insertion, grade II: slight resistance to insertion, grade III: moderate resistance to insertion, and grade IV: high resistance/impossible to insert.

The airway tube of the devices was connected to a closed circuit. The adequate airway placement of the LMA was said to be present if there was bilateral symmetrical chest expansion on manual ventilation, bilateral equal air entry on auscultation, and 6 square waveform tracings on the capnograph. Also, less than $20 \%$ loss of setting the tidal volume on a ventilator, lack of gastric insufflation, and a lack of audible leak at a peak airway pressure of $20 \mathrm{~cm}$ of water during manual ventilation were noted. Minor airway manipulations such as jaw thrust while inserting the device, head and neck flexion or extension, chin lift, and change in the depth of device needed for achieving adequate airway were noted. An optimal insertion of the device was deemed to be attained if both an effective airway and a successful gastric tube insertion were achieved. After two failed insertion attempts, the airway was secured with an appropriately sized endotracheal tube.

Anesthesia was maintained with $\mathrm{N}_{2} \mathrm{O} 67 \%, \mathrm{O}_{2} 33 \%$, with isoflurane 0.6-0.8\%, targeting end-tidal carbon dioxide $\left(\mathrm{EtCO}_{2}\right)$ of 35-45 mmHg and end-tidal minimum alveolar concentration of 1.0-1.2. Supplementation of vecuronium bromide $1 \mathrm{mg}$ intravenously was given as per requirement. Intramuscular diclofenac at a dose of $1.5 \mathrm{mg} / \mathrm{kg}$ body weight was given for pain relief, and injection ondansetron $75 \mu \mathrm{g} / \mathrm{kg}$ body weight intravenously was given as an antiemetic before the end of surgery. Ventilatory parameters like inspiratory tidal volume (ITV), expiratory tidal volume (ETV), $\mathrm{EtCO}_{2}$, peak airway pressure, and intrabdominal pressure were noted at one minute, five minutes, and 30 minutes after pneumoperitoneum and throughout the surgery. We calculated the leak fraction, i.e., ITV-ETV/ITV multiplied by 100 at five minutes post device insertion after connecting the patient to the ventilator.

OSP was measured after one minute and five minutes after pneumoperitoneum, and 30 minutes after connecting to a ventilator. We measured OSP by closing the circle system's expiratory valve at the fixed gas flow of $3 \mathrm{l}$ /minute and noting the airway pressure (maximum of $40 \mathrm{~cm} \mathrm{H}_{2} \mathrm{O}$ allowed) at which equilibrium was reached. Audible air leak near thyroid cartilage was assessed by auscultation, and the presence or absence of gastric insufflation by epigastric auscultation was also checked during leak pressure testing. We also recorded numbers of insertion attempts, time of insertion (holding the device at teeth level to obtain 46 square waveforms), the number of patients requiring manipulation or additional propofol for achieving effective airway, ease of insertion of the device (easy, slightly difficult, difficult, impossible).

At the end of the surgery, neuromuscular blockade was reversed with IV neostigmine and glycopyrrolate at a dose of $0.05 \mathrm{mg} / \mathrm{kg}$ and $0.01 \mathrm{mg} / \mathrm{kg}$ respectively. The device was removed in fully awake patients with their mouths open and suctioned continuously. We also assessed laryngopharyngeal morbidity by inspecting the device for blood stains or any sign of visible trauma to the patient's lips, tongue, teeth, or oral tissue, as this finding correlated with postoperative sore throat dysphagia and hoarseness.

\section{Statistical analysis}

Sample size calculation was based on the study by Alexiev et al. [5]. The observed mean sealing pressure was significantly higher in the BM group compared to the classic laryngeal mask airway group (29.98 \pm 8.51 vs. $24.50 \pm 6.19, \mathrm{p}=0.013$ ) [5]. Taking these values as a reference, the minimum required sample size with an $80 \%$ power of study and $5 \%$ level of significance was calculated to be 29 patients in each study group. Hence, we ultimately decided on a sample size of 60 (30 patients per group).

A total of 64 patients were enrolled by factoring in potential dropouts. Compiled data were tabulated and statistically analyzed using the SPSS Statistics software version 17.0 (IBM, Armonk, NY). Qualitative variables were expressed as frequencies/percentages and compared using the chi-squared/Mann-Whitney U test. Continuous variables were presented as mean \pm SD. All quantitative variables were compared using the Student's t-test/Mann-Whitney U test. A p-value $<0.05$ was considered statistically significant.

\section{Results}

Sixty-four patients were approached for enrollment in the study, out of which four patients were excluded. Finally, 60 participants were recruited for this randomized control trial that compared BM with LMA-P. One patient each in the BM group and LMA-P group was excluded from the study due to poor fit and excessive air leak. There was no statistical difference in terms of age, sex, and Mallampati scores between these groups (Table 1). 


\section{Cureus}

\begin{tabular}{|c|c|c|c|}
\hline Parameters & $\mathrm{BM}(\mathrm{n}=30)$ & LMA-P $(n=30)$ & P-value \\
\hline Age, years, mean $\pm S D$ & $32 \pm 13.67$ & $35 \pm 14.38$ & 0.576 \\
\hline Sex (female/male) & $14 / 16$ & $13 / 17$ & 0.795 \\
\hline Mallampati score (I/II/III) & $23 / 1 / 6$ & $26 / 2 / 2$ & 0.284 \\
\hline LMA size $3 / 4$ & $13 / 17$ & $9 / 21$ & 0.272 \\
\hline
\end{tabular}

\section{TABLE 1: Comparison of demographic data and supraglottic device sizes}

BM: Baska mask; LMA-P: laryngeal mask airway ProSeal; SD: standard deviation

We found a statistically significant difference in OSPs between the two devices ( $\mathrm{p}<0.001$ ), as shown in Table 2. Parameters regarding the performance of devices and their related complications are shown in Table 3.

\begin{tabular}{|c|c|c|c|}
\hline Parameters & BM $(n=30)$ & LMA-P $(n=30)$ & P-value \\
\hline OSP after 1 minute of CTV, mean \pm SD & $31.55 \pm 2.23 \mathrm{~cm} \mathrm{H}_{2} \mathrm{O}$ & $24.17 \pm 3.74 \mathrm{~cm} \mathrm{H}_{2} \mathrm{O}$ & $<0.001$ \\
\hline OSP after 5 minutes of CTV, mean \pm SD & $31.66 \pm 2.45 \mathrm{~cm} \mathrm{H}_{2} \mathrm{O}$ & $24.33 \pm 3.66 \mathrm{~cm} \mathrm{H}_{2} \mathrm{O}$ & $<0.001$ \\
\hline OSP after 30 minutes of CTV, mean \pm SD & $35.86 \pm 3.70 \mathrm{~cm} \mathrm{H}_{2} \mathrm{O}$ & $25.97 \pm 3.79 \mathrm{~cm} \mathrm{H}_{2} \mathrm{O}$ & $<0.001$ \\
\hline
\end{tabular}

TABLE 2: Comparison of OSP outcomes between the two groups

BM: Baska mask; LMA-P: laryngeal mask airway ProSeal; OSP: oropharyngeal seal pressure; CTV: connection to ventilator; SD: standard deviation

\begin{tabular}{|c|c|c|c|}
\hline Parameters & $B M(n=30)$ & LMA-P $(n=30)$ & P-value \\
\hline Number of attempts (1/2) & $24 / 6$ & $28 / 2$ & 0.254 \\
\hline Insertion time seconds, mean $\pm S D$ & $25.33 \pm 3.62$ & $28.77 \pm 6.6$ & 0.004 \\
\hline Additional dose of propofol & 3 & 0 & 0.237 \\
\hline Manipulation required & 7 & 3 & 0.299 \\
\hline \multicolumn{4}{|l|}{ Postoperative complication after 1 hour } \\
\hline Sore throat & 1 & 3 & 0.612 \\
\hline Hoarseness & 0 & 0 & - \\
\hline Dysphagia & 0 & 0 & - \\
\hline
\end{tabular}

\section{TABLE 3: The performance of devices and related complications}

BM: Baska mask; LMA-P: laryngeal mask airway ProSeal; SD: standard deviation

The two groups were comparable in terms of the number of insertion attempts, additional doses of propofol needed, the requirement of device manipulation, and postoperative laryngopharyngeal morbidity. The insertion time for LMA-P was significantly longer than that for BM ( $\mathrm{p}=0.004)$. Grade 1 ease of insertion in the BM group was observed in 23/30 cases (76.67\%), while in the LMA-P group, it was present in 26/30 cases (86.67\%), which was comparable between two devices $(\mathrm{p}=0.284)$.

The intraabdominal pressure, ITV, ETV, and EtCO2 values were comparable between the two groups in this 


\section{Cureus}

study. The mean value for peak airway pressure after 30 minutes was $21.07 \pm 2.49 \mathrm{~cm} \mathrm{H}_{2} \mathrm{O}$ in the BM group and $22.47 \pm 2.65 \mathrm{~cm} \mathrm{H}_{2} \mathrm{O}$ in the LMA-P group; the peak airway pressure trend increased in both the groups. The difference in peak airway pressure after 30 minutes was statistically significant ( $\mathrm{p}=0.016$ ) (Table 4).

\begin{tabular}{|c|c|c|c|}
\hline Parameters & BM $(n=30)$, mean $\pm S D$ & LMA-P $(n=30)$, mean $\pm S D$ & P-value \\
\hline \multicolumn{4}{|l|}{ Intraabdominal pressure } \\
\hline 1 minute after CTV & $0 \pm 0$ & $0 \pm 0$ & - \\
\hline 5 minutes after CTV & $0 \pm 0$ & $0 \pm 0$ & - \\
\hline After pneumoperitoneum & $12 \pm 0$ & $12 \pm 0$ & - \\
\hline 30 minutes after CTV & $12 \pm 0$ & $12 \pm 0$ & - \\
\hline \multicolumn{4}{|l|}{ Inspiratory tidal volume } \\
\hline 1 minute after CTV & $438.1 \pm 82.3 \mathrm{ml}$ & $438.1 \pm 82.3 \mathrm{ml}$ & 0.715 \\
\hline 5 minutes after CTV & $438.1 \pm 82.3 \mathrm{ml}$ & $438.1 \pm 82.3 \mathrm{ml}$ & 0.715 \\
\hline After pneumoperitoneum & $438.1 \pm 82.3 \mathrm{ml}$ & $438.1 \pm 82.3 \mathrm{ml}$ & 0.715 \\
\hline 30 minutes after CTV & $438.1 \pm 82.3 \mathrm{ml}$ & & 0.715 \\
\hline \multicolumn{4}{|l|}{ Expiratory tidal volume } \\
\hline 1 minute after CTV & $423.28 \pm 79.91 \mathrm{ml}$ & $423.28 \pm 79.91 \mathrm{ml}$ & 0.996 \\
\hline 5 minutes after CTV & $427.48 \pm 81.94 \mathrm{ml}$ & $427.48 \pm 81.94 \mathrm{ml}$ & 0.752 \\
\hline After pneumoperitoneum & $425.72 \pm 80.5 \mathrm{ml}$ & $422.63 \pm 57.64 \mathrm{ml}$ & 0.866 \\
\hline 30 minutes after CTV & $423.9 \pm 80.57 \mathrm{ml}$ & $421.63 \pm 57.34 \mathrm{ml}$ & 0.901 \\
\hline \multicolumn{4}{|l|}{ Peak airway pressure } \\
\hline 1 minute after CTV & $19.52 \pm 2.05 \mathrm{~cm} \mathrm{H}_{2} \mathrm{O}$ & $20.3 \pm 2.22 \mathrm{~cm} \mathrm{H}_{2} \mathrm{O}$ & 0.079 \\
\hline 5 minutes after CTV & $19.52 \pm 2.05 \mathrm{~cm} \mathrm{H}_{2} \mathrm{O}$ & $20.5 \pm 2.37 \mathrm{~cm} \mathrm{H}_{2} \mathrm{O}$ & 0.064 \\
\hline After pneumoperitoneum & $20.7 \pm 2.46 \mathrm{~cm} \mathrm{H}_{2} \mathrm{O}$ & $22.1 \pm 2.71 \mathrm{~cm} \mathrm{H}_{2} \mathrm{O}$ & 0.035 \\
\hline 30 minutes after CTV & $21.0 \pm 2.49 \mathrm{~cm} \mathrm{H}_{2} \mathrm{O}$ & $22.5 \pm 2.65 \mathrm{~cm} \mathrm{H}_{2} \mathrm{O}$ & $0.016^{*}$ \\
\hline
\end{tabular}

\section{TABLE 4: Ventilatory parameters after connection to a ventilator (CTV)}

*Significant p-value

BM: Baska mask; LMA-P: laryngeal mask airway ProSeal; CTV: connection to ventilator; SD: standard deviation

In this study, the mean value for leak fraction at five minutes of connection to ventilator was $2.5 \pm 2.4 \%$ in the BM group and $3.49 \pm 3 \%$ in the LMA-P group. The difference in leak pressure between groups was not statistically significant $(\mathrm{p}=0.174)$.

\section{Discussion}

Our study compared the BM with LMA-P in patients undergoing elective laparoscopic cholecystectomy. The principal finding of our study was a significant difference between OSP and insertion time of the BM as compared to LMA-P. Most of the measured variables like patient age, sex, Mallampati score, sizes of LMA, duration of surgery, and intraabdominal pressure during laparoscopic surgery were comparable in both groups. There was a significant difference between peak airway pressure after 30 minutes of connecting to the ventilator, but other ventilatory parameters were comparable.

In our study, both the devices were easy to insert; however, 23 (76.67\%) patients in the BM group and 26 (86.67\%) patients in the LMA-P group had grade 1 ease of insertion. The ease of insertion between the two groups was comparable with a p-value of 0.284 . Our results were similar to the findings of Kachakayala et al. They also found the ease of insertion comparable between these two devices [6]. In the BM group, $23.33 \%$ of 
patients required manipulation, while $10 \%$ of patients required manipulation in the LMA-P group. This difference between the two groups was not statistically significant $(\mathrm{p}=0.299)$. The frequency of manipulation was relatively less in our study when compared to Alexiev et al., where additional maneuvers were required in $45 \%$ of the patients [5].

Our results suggested that the mean time for insertion in the BM group ( $25.33 \pm 3.62$ seconds) was comparatively shorter than that in the LMA-P group ( $28.77 \pm 6.6$ seconds) ( $p=0.004)$, which is very similar to the findings in other studies [5-10]. The reason behind the quick and easy insertion of BM may be attributed to its manufacturing design, which includes a cuffless membrane and a tab to increase the palatopharyngeal curve to assist insertion. However, Reddy et al. reported significantly increased insertion time for the BM group when compared to the LMA-P group [11].

Both BM and LMA-P are supraglottic airway devices with an in-situ gastric channel. It is well-known that LMA-P has higher seal pressures than i-gel, and BM also has higher seal pressure than i-gel $[12,13]$. The higher seal pressure of LMA-P may be due to the additional posterior cuff; however, BM lacks any such cuff. We observed higher OSP with BM compared to LMA-P. The mean OSP at different time intervals varied from 31.55 to $35.86 \mathrm{~cm} \mathrm{H}_{2} \mathrm{O}$ in BM, while in the LMA-P group, it was 24.17 to $25.97 \mathrm{~cm} \mathrm{H}_{2} \mathrm{O}$ ( $\mathrm{p}<0.001$ ). This finding was corroborated in the study by Singh et al., who observed OSP of $30.25 \pm 8.34 \mathrm{~cm} \mathrm{H}_{2} \mathrm{O}$ for the BM and $23.50 \pm 4.05 \mathrm{~cm} \mathrm{H}_{2} \mathrm{O}$ for the LMA-P [7]. Also, our findings are similar to those by Dhanasekaran et al. in 2019 and Ali et al. in 2013; both of them affirmed that the BM has significantly higher OSP than the LMA-P $[8,10]$.

The OSP trend kept increasing in the BM group much more than the LMA-P group during surgery in our study, which is a new finding. This may be attributed to the BM having a membranous cuff, and its seal pressure directly correlating with the increase in intermittent positive pressure ventilation. It is a wellknown fact that laparoscopic cholecystectomy requires higher intermittent positive pressure ventilation, including higher positive end-expiratory pressure [14]. There was no significant difference in laryngopharyngeal morbidity between the groups, which is in line with other studies [8-10].

Our study has some limitations. We did not include obese and pediatric patients due to the non-availability of suitable sizes of the BM. Moreover, this was a single-blinded study.

\section{Conclusions}

Based on our findings, the BM provides higher OSP than the LMA-P and offers better protection against aspiration in laparoscopic cholecystectomy. Hence, we emphasize that the BM is a safer alternative than LMA-P in laparoscopic cholecystectomy.

\section{Additional Information}

\section{Disclosures}

Human subjects: Consent was obtained or waived by all participants in this study. Institutional Ethics Committee, Vardhman Mahavir Medical College and Safdarjung Hospital issued approval (IEC/VMMC/SJH/Thesis/Oct 2017-015). Animal subjects: All authors have confirmed that this study did not involve animal subjects or tissue. Conflicts of interest: In compliance with the ICMJE uniform disclosure form, all authors declare the following: Payment/services info: All authors have declared that no financial support was received from any organization for the submitted work. Financial relationships: All authors have declared that they have no financial relationships at present or within the previous three years with any organizations that might have an interest in the submitted work. Other relationships: All authors have declared that there are no other relationships or activities that could appear to have influenced the submitted work.

\section{References}

1. Park SK, Ko G, Choi GJ, Ahn EJ, Kang H: Comparison between supraglottic airway devices and endotracheal tubes in patients undergoing laparoscopic surgery: a systematic review and meta-analysis. Medicine (Baltimore). 2016, 95:e4598. 10.1097/MD.0000000000004598

2. Keller C, Brimacombe JR, Keller K, Morris R: Comparison of four methods for assessing airway sealing pressure with the laryngeal mask airway in adult patients. Br J Anaesth. 1999, 82:286-7. 10.1093/bja/82.2.286

3. Alexiev V, Salim A, Kevin LG, Laffey JG: An observational study of the Baska ${ }^{\circledR}$ mask: a novel supraglottic airway. Anaesthesia. 2012, 67:640-5. 10.1111/j.1365-2044.2012.07140.x

4. Shi YB, Zuo MZ, Du XH, Yu Z: Comparison of the efficacy of different types of laryngeal mask airways in patients undergoing laparoscopic gynecological surgery (Article in Chinese). Zhonghua Yi Xue Za Zhi. 2013, 93:1978-80.

5. Alexiev V, Ochana A, Abdelrahman D, et al.: Comparison of the Baska( $\left.{ }^{\circledR}\right)$ mask with the single-use laryngeal mask airway in low-risk female patients undergoing ambulatory surgery. Anaesthesia. 2013, 68:1026-32. 10.1111/anae. 12356

6. Kachakayala RK, Bhatia P, Singh S, Dwivedi D: A comparative study of supraglottic airway devices Baska 


\section{Cureus}

mask and ProSeal-laryngeal mask airway in short gynaecological procedures. J Res Med Sci. 2019, 8:285-9. 10.18203/2320-6012.ijrms20195924

7. Singh B, Singh AP, Attri JP: Randomized controlled trial to compare Baska ${ }^{\circledR}$ mask versus ProSeal laryngeal mask airway for general anesthesia with intermittent positive pressure ventilation. Anesth Essays Res. 2020, 14:25-8. 10.4103/aer.AER_23_20

8. Dhanasekaran R, Mehta GD, Parameswari A: A prospective randomized comparative study between Baska mask, Proseal LMA and I Gel during positive pressure ventilation in laparoscopic cholecystectomy. JARSS. 2019, 27:106-11. 10.5222/jarss.2019.54254

9. Kumar EJ, Anand GV, Shaji A: A comparative study of Baska mask versus Proseal LMA in elective sterilisation surgeries. IAIM. 2019, 6:108-13.

10. Ali S, Al-Rawahi S, Aziz H, Malik AM, Khan R, Kaul N: A comparative analysis of the Baska ${ }^{\circledR}$ mask vs. Proseal ${ }^{\circledR}$ laryngeal mask for general anesthesia with IPPV. Anesth Pain Intensive Care. 2013, 17:233-36.

11. Reddy P, KC Shivkumara, Madhu M, Osheen M: Baska mask, I-Gel supraglottic airway device and LMAproseal in spontaneously breathing, anaesthetised children during elective surgeries: Ease of insertion of the three devices. Eur J Mol Clin Med. 2022, 1:831-5.

12. Maitra S, Baidya DK, Arora MK, Bhattacharjee S, Khanna P: Laryngeal mask airway ProSeal provides higher oropharyngeal leak pressure than i-gel in adult patients under general anesthesia: a meta-analysis. J Clin Anesth. 2016, 33:298-305. 10.1016/j.jclinane.2016.04.020

13. Choi SR, Lee TY, Kim SW, Park SY, Chung CJ, Kim JH: Comparison of clinical performance of i-gel| $\mathbf{X}$ and Baska Mask区 during laparoscopic cholecystectomy. Korean J Anesthesiol. 2019, 72:576-82. 10.4097/kja.19195

14. Zundert T, Gatt S: The Baska Mask ${ }^{\circledR}$-a new concept in self-sealing membrane cuff extraglottic airway devices, using a sump and two gastric drains: a critical evaluation. J Obstet Anesth Crit Care. 2012, 2:23-30. 10.4103/2249-4472.99313 